\title{
Status and Challenges of Medical Waste Management in Hospitals of Iran
}

\author{
Akbar Eslami ${ }^{\text {a }}$, Parviz Nowrouz ${ }^{\text {b* }}$, Samira Sheikholeslami ${ }^{\mathrm{c}}$ \\ ${ }^{a}$ Environmental and Occupational Hazards Control Research Center, Shahid Beheshti University of Medical Sciences, Tehran, Iran. \\ ${ }^{b}$ Environmental Health Engineering, School of public health, Shahid Beheshti University of Medical Sciences, Tehran, Iran.
}

${ }^{c}$ Environmental Health Engineering, Ministry of Health and Medical Education, Tehran, Iran.

Received 07 August 2017; Accepted 26 September 2017

\begin{abstract}
Medical waste is of great importance due to its hazardous nature that can cause undesirable effects on humans and the environment. This study focuses on medical waste management in hospitals of Iran. Data were collected based on questionnaires and for self-report of medical waste management. The results along with other information were sent to the ministry of health network system. Results indicated that the mean generation rate of non-hazardous and sharp and infectious and total wastes in Iran were, respectively, 1.84, 1.09 (36.9\% of total waste generated) and $2.98 \mathrm{~kg} / \mathrm{bed} / \mathrm{day}$. Chemical waste generation rate in Iran is $0.02 \mathrm{~kg} / \mathrm{bed} / \mathrm{day}(0.68 \%)$ that relative to infectious waste and total waste generation rate is much lower which could be due to improper segregation of medical wastes. There is significant differences between private and governmental hospitals, in terms of infectious and sharp waste generation rates $(\mathrm{P}=0.027)$. Also there are significant differences between specialized and general hospitals in group of non-hazardous waste $(\mathrm{P}=0.039)$, infectious waste $(\mathrm{P}=0.001)$ and total waste generation rate $(\mathrm{P}=0.02) .65 .41 \%$ of governmental hospitals used autoclave for infectious waste treatment. In the private and governmental hospitals $14.8 \%$ and $24.29 \%$, respectively not have any treatment devices and hazardous waste was disposed without treatment.
\end{abstract}

Keywords: Medical Waste Management; Infectious Waste Treatment; Hospital; Iran.

\section{Introduction}

Medicine is one of the significant sectors showing improvement throughout the world during recent decades [1]. Medical waste (MW) constitutes a significant fraction of infectious wastes, which are potentially dangerous since they may contain pathogenic agents. The production of these wastes will continue to be an on-going phenomenon as long as there are human activities. There has been an increase in the public concern about the management of hospital waste on a global basis especially in developing countries where both financial and technological resources on medical waste management are still lacking [2, 3]. The World Health Organization designates medical waste as the waste generated by health-care activities that can include a wide range of materials, such as used needles and syringes, soiled dressings, body parts, diagnostic samples, blood, chemicals, pharmaceuticals, medical devices and radioactive materials. [4]. When hazardous health care wastes are not properly managed, exposure to them could lead to infections, infertility, genital deformities, hormonally triggered cancers, mutagenicity, dermatitis, asthma and neurological disorders in children;

\footnotetext{
* Corresponding author: nowrouzp@gmail.com

DOI: http://dx.doi.org/10.21859/cej-030910
}

$>$ This is an open access article under the CC-BY license (https://creativecommons.org/licenses/by/4.0/).

(C) Authors retain all copyrights. 
typhoid, cholera, hepatitis, AIDS and other viral infections may be transferred through sharps contaminated with blood [5].

In addition, it is not often clear whether household type wastes (non-hazardous wastes) are also included in the medical wastes. For example, in Jordan, medical waste is grouped into: pathological waste, and sharp and infectious wastes [6]. In Taiwan, medical wastes are classified into infectious wastes, and general medical wastes without clearly specifying the contents of these two categories. The former group is further classified into infectious wastes, pathological wastes, and sharp objects [7]. In China, medical wastes are grouped into tissues, infectious wastes, sharps, chemical wastes and medicine wastes [2]. In Cameroon, medical wastes are classified into general wastes, sharps, infectious wastes and chemical/pharmaceutical wastes [8]. According to the United States Environmental Protection Agency (USEPA, 2011), medical wastes contain all waste materials generated by health-care facilities, such as hospitals, clinics, physician's offices, dental practices, blood banks, and veterinary hospitals/clinics, as well as medical research facilities and laboratories. The definition, according to the USEPA, includes but is not limited to, blood-soaked bandages, culture dishes and other glassware, discarded surgical gloves, discarded surgical instruments, discarded hypodermic needles (e.g., medical sharps), microbiological cultures, stocks, swabs used to inoculate cultures and withdrawn body organs after a surgery [4]. Because of the variability in the MW definitions, a rather wide and diverse range of MW generation rates has been reported in the literature. Sometimes, it is not clear whether non-hazardous (household type) medical wastes are included in the total MW generation rates that are reported. Survey of waste generation rate will be the basis for identifying opportunities and developing waste minimization, cost reduction plans, and an effective waste management program. Several surveys have addressed typical health-care related waste generation across several countries. However, the generation of health-care waste differs from country to country [9].

Several studies have investigated the medical waste generation. For example, in Nanjing of China, researchers found that the medical waste generation rate ranges from 0.5 to $0.8 \mathrm{~kg} / \mathrm{bed}$ day with a weighted average of $0.68 \mathrm{~kg} / \mathrm{bed} / \mathrm{day}$ [2]. In Lebanon, the obtained results showed that the average generation rate of large private hospitals was $2.45 \mathrm{~kg}$ per occupied bed per day [10]. In other study in China, the hospital medical waste generation rate was estimated based on diagnosis-related groups [11]. An inventory of all 58 healthcare facilities in the province of Isfahan, Iran, was performed and results indicated that the waste generation rates for total waste, general waste, infectious, and sharp wastes were $3.03,1.84,0.75$, and $0.17 \mathrm{~kg} /$ active bed/day, respectively. Also as for the treatment of medical wastes, only $6.9 \%$ of centers were equipped with autoclave [12]. In the south of Brazil a total of 91 healthcare facilities were surveyed to provide information about the management of medical wastes. Results showed that average generation rates of total and infectious-biological wastes in the hospitals were estimated to be 3.245 and $0.570 \mathrm{~kg} / \mathrm{bed}$-day, respectively [13]. In Tabriz as a major city northwest of Iran the 25 active hospitals were surveyed for the management of medical wastes. The results indicated that the average (weighted mean) of total medical waste, hazardous-infectious waste, and general waste generation rates in Tabriz city is 3.48, 1.039 and, $2.439 \mathrm{~kg} / \mathrm{bed}$-day, respectively [14]. Safe disposal of infectious medical wastes is a problem of considerable scope, with the WHO stating that "at present, there are practically no environmentally friendly, low-cost options for safe disposal of infectious wastes". In the United States, studies have found that $49-60 \%$ of medical waste is incinerated, $20-37 \%$ is autoclaved, and $4-5 \%$ is treated by other technologies. However, concerns over air pollution have raised questions about the suitability of incineration as treatment method. Further, medical waste contains a significantly higher plastic content than typical municipal solid waste, and as a result the combustion of medical waste leads to the formation of polychlorinated dibenzo-pdioxins (dioxins) and polychlorinated dibenzofurans (furans), both highly toxic substances. This has led to an increased focus on alternate treatment methods such as autoclaving and microwaving to kill any pathogens present [15].

In Iran, According to the 2005 Waste Management Act, executive management of all non-industrial and special waste is the responsibility of municipalities. Also, executive management of the industrial and hazardous waste, will be the responsibility of the producer, but supervised and administered by the Department of Environment. If the special and industrial waste turn into general waste, it will become the responsibility of municipalities. Medical waste is managed under the regulations and methods of the executive management of medical wastes in healthcare facility, which regulates the behavior of hospitals on medical waste collection, segregation, storage, transport, and treatment. Some studies have been carried out in Iran about the medical wastes management, such as qualitative study of the causes of improper segregation of infectious waste in Shiraz. This research, found that managerial weakness was an important factor in suboptimal disposal of medical waste [16]. In other study in Tabriz it was found that the total hazardous-infectious waste was $29.89 \%$ of total medical waste generated [14]. In other study in Karaj, they obtained that the generation rates of hazardous-infectious waste was $2.3 \mathrm{~kg} / \mathrm{bed}$-day (57\%) [17]. But there is no comprehensive investigation about the status of hospital waste management in Iran. Therefore, it is a necessity to evaluate the national condition of hospital waste management, where this is the key objective of the present study.

\section{Methodology}

The present study is based on collected information for all 31 provinces of Iran. In this descriptive cross-sectional study, 877 active hospitals were selected to survey. The hospitals were related to governmental and private sectors. All 
of hospitals that had access to Ministry of Health and Medical Education network were selected in current study. Among the selected hospitals, 837 hospitals participated in this study.

\subsection{Data Collection}

Data were gathered based on the instructions of medical waste treatment and self-report of hospitals, which were announced by the Ministry of Health and Medical Education to hospitals [18]. In this method, forms and questionnaires were sent to all hospitals via the ministry of health and medical education web based network system.

The most important information that must be collected includes the following:

- Number of beds (number of active beds in hospitals)

- Type of hospital (i.e., private, governmental, related to other organizations, etc.)

- Total waste generation rate $(\mathrm{kg} / \mathrm{day})$

- Infectious and sharp waste generation rate $(\mathrm{kg} / \mathrm{day})$

- Chemical waste generation rate $(\mathrm{kg} / \mathrm{day})$

- Treatment methods (such as autoclave, hydroclave, chemical, microwave, etc.)

Therefore, to complete the questionnaire and obtain the required information, in accordance with the instructions of the Ministry of Health, environmental health experts calculated the amount of the waste generation rate in three groups of non-hazardous or general waste, infectious and sharp, and chemical waste. In this case, the environmental health experts directly weighted $89.4 \%$ of the hospital's waste and calculated $10.6 \%$ of waste based on the storage tank volume. Then, the average result of weighting along with the number of active beds, treatment method, and other information was reported to the Ministry of Health and Medical Education. The information was obtained in August and December, 2016, and analyzed later.

\subsection{Data Verification and Confirmation}

To ensure the accuracy of the data and information, a separate form was sent to the hospitals to confirm and verify the submitted data. This form along with questionnaire were approved by environmental health officer, hospital manager, medical equipment manager, and then sealed and confirmed. Therefore, hospitals were responsible to provide correct information for the Ministry of Health and Medical Education.

\subsection{Analysis}

In the first place we presented the descriptive analyses by provinces. We tried to compare waste generation means between two groups of hospitals (governmental versus private; specialized versus general). To this purpose, normality of the data distribution was checked by Smirnoff-Kolmogorov and Q-Q plot method. We found that data was not normally distributed. Therefore non-parametric tests (Mood's median test, Mann-Whitney test) were employed to compare the means.. Nonparametric tests, which are appropriate for non-normal data, are based on the comparison of the ranks of data, rather on the comparison of the original data themselves. The cut-off point for the statistical significance was set at 5\% ( $\mathrm{P}<0.05)$. Statistical analysis was performed using SPSS version 18.

\section{Results and Discussion}

\subsection{Generation Rate}

Different groups of waste are produced from the various activities performed in the hospitals. Nonhazardous waste generated in a hospital is related to food preparation, administrative departments, and landscaping. This type of waste is similar to household waste and city waste. In hospitals, different kinds of therapeutic procedures are carried out that results in the production of infectious wastes, sharp waste, pharmaceutical wastes, and chemical materials which are considered to be hazardous wastes. The total amount of waste generated in hospitals is associated with various factors such as the number of beds, economic conditions, social and cultural status of the patients and the type or the size of the institution [7, 19]. It is generally accepted that $\mathrm{kg} / \mathrm{bed}$-day is the best available basis for hospital waste production comparison, with studies finding that the number of beds in service strongly relates to the amount of medical waste produced at similar hospital facilities [20]. Mean, median and percentage of hospital waste generation rate in provinces of Iran in the groups of non-hazardous waste, sharp and infectious, and chemical waste are shown in Table 1. The hospital waste generation rates ranged from 0.91 to $3.27 \mathrm{~kg} / \mathrm{bed} /$ day for general medical wastes and from 0.48 to $1.78 \mathrm{~kg} / \mathrm{bed} / \mathrm{day}$ for infectious and sharp wastes. In Tehran as the capital of Iran, total amount of waste generation and infectious waste generation rate are 3.38 and $1.22 \mathrm{~kg} / \mathrm{bed} /$ day, respectively. Alborz province had the greatest hazardous-infectious and Qazvin had the greatest general waste generation rates, namely 1.78 and $3.27 \mathrm{~kg} / \mathrm{bed} / \mathrm{day}$, respectively.

Among the provinces that were studied, the lowest hazardous-infectious waste generation rate belonged to East Azarbayjan province $(0.48 \mathrm{~kg} / \mathrm{bed}$-day). Chemical waste generation mean rate in Iran is $0.02 \mathrm{~kg} / \mathrm{bed} / \mathrm{day}$ that is relative to infectious waste and total waste generation rate is much lower which could be due to improper segregation of solid 
wastes. Generation rate of the medical waste differs not only from country to country but also within countries. The differences of generation rates among hospitals and provinces indicate that waste generation depends on numerous factors, such as established waste, management methods, type of health-care establishment, hospital specializations, proportion of reusable items used in health care, proportion of patients treated on a day-care basis, size of the healthcare facility, medical waste segregation program, and the economic, social, and the general condition of the area where the hospital is situated. These results were compared with the generation rates determined in other studies from different cities in Iran, as well as from different countries. In the study performed in Tabriz city and southern of Iran, the average generation rate of medical waste were, respectively, about 3.48 and $3.79 \mathrm{~kg} / \mathrm{bed} /$ day $[14,21]$. In Shiraz and Tehran city, the average generation rate of medical waste was about $4.45 \mathrm{~kg} / \mathrm{bed} / \mathrm{day}$ and $2.71 \mathrm{~kg} / \mathrm{bed} / \mathrm{day}$, respectively. [19]. That mostly are in range of current study which total medical waste generation mean rate are between 1.58 to $4.2 \mathrm{~kg} / \mathrm{bed} / \mathrm{day}$. A study conducted by Cheng et al. (2009) indicated that the total waste generation rate was between 2.41 to 3.26 $\mathrm{kg} / \mathrm{bed} / \mathrm{day}$ and infectious waste generation rate was between 0.19 to $0.88 \mathrm{~kg} / \mathrm{bed} / \mathrm{day}$ in Taiwan [7]. Birpinar et al., 2008 investigated 192 hospitals in Turkey and reported an average generation rate of $0.63 \mathrm{~kg} / \mathrm{bed}$ day [1]. Tsakona et al. reported an average generation in Greece of about $1.9 \mathrm{~kg} / \mathrm{bed}$ day [22]. Komilis et al. reported that the average hazardous generation rate was about $0.12-0.72 \mathrm{~kg} / \mathrm{bed}$ day in Greece [4]. According to a summary by Diaz et al. (2008), the total amount of healthcare waste generated in selected hospitals in developing countries varied from 0.016 to $3.23 \mathrm{~kg} / \mathrm{bed}$ day, and the percentage of infectious waste in the total healthcare waste stream in developing countries was about $63 \%$ (from 0.01 to $0.65 \mathrm{~kg} / \mathrm{bed}$ day) [23].

Table 1. Average medical waste generation rate in hospitals of Iran $(\mathrm{kg} / \mathrm{bed} / \mathrm{day})$

\begin{tabular}{|c|c|c|c|c|c|c|c|c|c|c|c|c|}
\hline \multirow{2}{*}{ Province } & \multirow[b]{2}{*}{$\mathbf{N}$} & \multicolumn{3}{|c|}{ Non-hazardous } & \multicolumn{3}{|c|}{ Infectious and sharp } & \multicolumn{3}{|c|}{ Chemical } & \multicolumn{2}{|c|}{ Total } \\
\hline & & Mean & Median & $\%$ & Mean & Median & $\%$ & Mean & Median & $\%$ & Mean & Median \\
\hline Azerbaijan, East & 44 & 1.76 & 1.67 & 78.1 & 0.48 & 0.43 & 21.2 & 0.01 & 0.00 & 0.27 & 2.26 & 2.21 \\
\hline Azerbaijan, West & 30 & 1.94 & 1.6 & 60.4 & 1.25 & 1.19 & 38.7 & 0.00 & 0.00 & 0.15 & 3.22 & 3.08 \\
\hline Ardabil & 15 & 2.08 & 1.97 & 69 & 0.91 & 0.91 & 30.2 & 0.02 & 0.00 & 0.73 & 3.01 & 2.95 \\
\hline Alborz & 14 & 1.69 & 1.75 & 47.7 & 1.78 & 1.75 & 50.3 & 0.04 & 0.03 & 1.23 & 3.53 & 3.25 \\
\hline Bushehr & 15 & 1.44 & 0.89 & 47 & 1.44 & 1.39 & 46.9 & 0.12 & 0.11 & 4.02 & 3.06 & 2.50 \\
\hline Chahar Mahaal and Bakhtiari & 9 & 3.09 & 3.23 & 75.5 & 1.00 & 1.11 & 24.5 & 0.00 & 0.00 & 0.00 & 4.10 & 4.38 \\
\hline Fars & 27 & 1.74 & 1.46 & 57.9 & 1.25 & 1.05 & 41.5 & 0.00 & 0.00 & 0.14 & 3.00 & 2.71 \\
\hline Gilan & 31 & 1.6 & 1.73 & 60.3 & 1.03 & 1.00 & 38.9 & 0.01 & 0.00 & 0.43 & 2.65 & 2.83 \\
\hline Golestan & 22 & 1.45 & 1.33 & 61.6 & 0.84 & 0.80 & 35.9 & 0.00 & 0.00 & 0.00 & 2.35 & 2.13 \\
\hline Hamadan & 21 & 1.38 & 1.28 & 54.4 & 1.15 & 1.16 & 45.6 & 0.00 & 0.00 & 0.00 & 2.53 & 2.50 \\
\hline Hormozgan & 20 & 2.02 & 1.6 & 68 & 0.92 & 0.82 & 31.0 & 0.03 & 0.01 & 0.99 & 2.98 & 2.36 \\
\hline Ilam & 11 & 0.97 & 0.79 & 47.7 & 0.99 & 0.89 & 48.7 & 0.03 & 0.03 & 1.57 & 2.03 & 1.97 \\
\hline Isfahan & 59 & 2.11 & 1.68 & 58.7 & 1.45 & 1.24 & 40.2 & 0.02 & 0.00 & 0.48 & 3.59 & 3.36 \\
\hline Kerman & 29 & 1.6 & 1.47 & 56.7 & 1.13 & 0.94 & 40.1 & 0.01 & 0.00 & 0.19 & 2.82 & 2.55 \\
\hline Kermanshah & 23 & 1.88 & 1.54 & 61.9 & 1.06 & 0.91 & 35.1 & 0.03 & 0.01 & 1.02 & 3.03 & 2.41 \\
\hline Khorasan North & 9 & 1.22 & 0.93 & 51.8 & 1.07 & 0.82 & 45.7 & 0.00 & 0.00 & 0.19 & 2.35 & 2.25 \\
\hline Khorasan Razavi & 55 & 1.68 & 1.63 & 63.1 & 0.95 & 0.88 & 35.7 & 0.01 & 0.00 & 0.39 & 2.66 & 2.53 \\
\hline Khorasan South & 12 & 1.66 & 1 & 56.3 & 1.25 & 0.99 & 42.2 & 0.01 & 0.00 & 0.45 & 2.95 & 2.12 \\
\hline Khuzestan & 52 & 2.22 & 1.84 & 65.3 & 1.16 & 0.88 & 34.0 & 0.01 & 0.00 & 0.41 & 3.40 & 2.75 \\
\hline Kohgiluyeh and Boyer-Ahmad & 9 & 1.89 & 1.43 & 62 & 1.06 & 0.94 & 34.8 & 0.07 & 0.03 & 2.15 & 3.05 & 2.72 \\
\hline Kurdestan & 16 & 1.5 & 1.4 & 60.3 & 0.95 & 0.98 & 38.0 & 0.01 & 0.01 & 0.35 & 2.50 & 2.46 \\
\hline Lorestan & 23 & 2.33 & 2.25 & 68.3 & 1.03 & 0.91 & 30.1 & 0.02 & 0.00 & 0.66 & 3.42 & 3.45 \\
\hline Markazi & 19 & 1.8 & 1.56 & 58.5 & 1.23 & 0.94 & 40.0 & 0.03 & 0.01 & 0.82 & 3.08 & 2.55 \\
\hline Mazandaran & 41 & 1.86 & 1.73 & 65.2 & 0.96 & 0.86 & 33.7 & 0.02 & 0.00 & 0.58 & 2.86 & 2.59 \\
\hline Qazvin & 14 & 3.27 & 2.46 & 77.8 & 0.91 & 1.00 & 21.5 & 0.02 & 0.01 & 0.43 & 4.20 & 3.53 \\
\hline Qom & 10 & 2.39 & 1.89 & 58.2 & 1.69 & 1.88 & 41.0 & 0.01 & 0.00 & 0.24 & 4.11 & 3.44 \\
\hline Semnan & 10 & 0.91 & 0.95 & 57.7 & 0.64 & 0.56 & 40.6 & 0.02 & 0.02 & 1.14 & 1.58 & 1.48 \\
\hline Sistan and Baluchestan & 14 & 2.1 & 1.43 & 64.5 & 1.11 & 1.11 & 34.2 & 0.01 & 0.00 & 0.38 & 3.26 & 2.21 \\
\hline Tehran & 152 & 2.11 & 1.92 & 62.3 & 1.22 & 1.14 & 36.2 & 0.03 & 0.01 & 0.85 & 3.38 & 3.18 \\
\hline Yazd & 19 & 1.89 & 1.5 & 70.9 & 0.75 & 0.74 & 28.3 & 0.02 & 0.01 & 0.65 & 2.67 & 2.25 \\
\hline Zanjan & 12 & 1.59 & 1.6 & 59.9 & 1.05 & 1.04 & 39.7 & 0.01 & 0.00 & 0.28 & 2.66 & 2.92 \\
\hline Average in Iran & - & 1.84 & 1.6 & 61.52 & 1.09 & 1.01 & 36.9 & 0.02 & 0.01 & 0.68 & 2.98 & 2.70 \\
\hline
\end{tabular}


In Table 2, hospital waste mean generation rate is presented based on the private and governmental hospitals and also based on their activity (general and specialized). The results of the survey indicate that the mean generation rates for total medical waste, hazardous-infectious waste, and chemical waste in private hospitals are 3.1, 0.99 and 0.03 $\mathrm{kg} / \mathrm{bed} /$ day and in governmental hospitals are 3.07, 1.13 and $0.02 \mathrm{~kg} / \mathrm{bed} /$ day, respectively. Also, the mean total amount of waste generated in general hospitals was higher than specialized hospitals.

Table 2. Hospital waste generation rate in Iran $(\mathrm{kg} / \mathrm{bed} / \mathrm{day})$

\begin{tabular}{cccccccccc}
\hline \multirow{2}{*}{ Hospital } & $\mathbf{N}$ & \multicolumn{2}{c}{ Non-hazardous } & \multicolumn{2}{c}{ Infectious and sharp } & \multicolumn{2}{c}{ Chemical } & \multicolumn{2}{c}{ Total } \\
\cline { 3 - 10 } & & Mean & Median & Mean & Median & Mean & Median & Mean & Median \\
\hline Private & 135 & 2.07 & 1.59 & 0.99 & 0.84 & 0.03 & 0.0 & 3.1 & 2.5 \\
Governmental & 702 & 1.89 & 1.63 & 1.13 & 0.98 & 0.02 & 0.0 & 3.07 & 2.75 \\
Specialized & 136 & 1.7 & 1.56 & 0.99 & 0.75 & 0.02 & 0.0 & 2.75 & 2.61 \\
General & 701 & 1.94 & 1.63 & 1.12 & 0.99 & 0.02 & 0.0 & 3.10 & 2.75 \\
\hline
\end{tabular}

Statistical analysis indicated that There are significant differences between private and governmental hospitals, in terms of infectious and sharp waste generation rates $(\mathrm{P}=0.027)$. Also there are significant differences between specialized and general hospitals in group of non-hazardous waste $(\mathrm{P}=0.039)$, infectious and sharp waste $(\mathrm{P}=0.001)$ and total waste generation rate $(\mathrm{P}=0.02)$. There were no significant differences between private and governmental hospitals in total and non-hazardous and chemical waste generation rate. Also there were no significant differences in chemical waste generation rate generally.

It was concluded that, medical waste generation rate in hospitals of Iran is comparatively high. This variability can be indicative either of inappropriate waste separation practices within each hospital or of the fact that, apart from total beds, other factors may influence medical waste generation in a hospital, such as external patients, bed occupancy, number of lab tests or surgeries performed daily and number and capacity of individual clinics and departments within each hospital and lack of a plan for waste minimization in hospitals. For example, Komilis and Katsafaros showed that MW generated from a bio-pathology laboratory and an emergency department of a public HCF in Greece was highly correlated to the number of lab tests performed daily and the number of examinees per day, respectively [24]. Relatively good positive correlations between MW generation rates and various hospitals parameters (e.g. total beds, occupied beds, lab tests, hospital employees, nurses, doctors, surgeries) were calculated by Sanida et al. (2010) in hospitals of North Greece too [25].

\subsection{Percentage of Infectious and Sharp Waste in the Total Medical Waste Stream}

The percentage of infectious and sharp waste was determined in all of the studied provinces and the results are presented in Table 1. The findings showed that percentage of infectious and sharp waste at all levels of hospitals were between 21.2\% (East Azarbayjan province) to 50.3\% (Alborz province) and on average 36.9\% that are much greater than what is recommended by the WHO. The WHO has estimated that 75\%-90\% (85\%) of the waste produced by healthcare providers and hospitals is general health-care waste or non-hazardous waste and that the remaining $10 \%-25 \%$ is hazardous waste and $10 \%$ is hazardous-infectious waste [26]. Another study conducted in hospitals of Tabriz city in Iran reported that the amount of infectious and sharp waste was $29.89 \%$ and the amount of general waste was $70.11 \%$ [14]. Bazrafshan and Mostafapoor in Sistan Baluchestan province of Iran found that $52.8 \%$ of medical waste generation was infectious and sharps and 47.2\% was general waste [27]. Other studies in Thailand, Vietnam and Botswana showed that infectious and sharp waste generation percentage were $22 \%$ and $10 \%$ and $39.13 \%$ [28, 29]. The different proportions of general waste and hazardous waste can be explained by the different implemented medical waste management systems in hospitals. The amount of hazardous-infectious waste and sharp waste in the total medical waste stream illustrates the importance of implementing a precise segregation program that utilizes standard color-coded plastic bags or containers and educating programs for hospital staff. It is very clear that in hospitals of Iran, the portion of infectious and sharp waste, also their generation rate are very high. It can be dependent upon various factors such as improper segregation, and lack of a planning and education program for waste minimization. High generation of infectious and sharp waste can raise a significant cost for the treatment and disposal of medical waste in any society.

\subsection{Percentage of Chemical Waste in the Total Medical Waste Stream}

Chemical waste portion in total medical waste was determined in all of the studied provinces and the results are presented in Table 1. The findings showed that chemical waste at all levels of hospitals were between 0.0 to $4.02 \%$ (an average about $0.68 \%$ ). These values are lower than what the WHO statistical analysis demonstrate (i.e. $5 \%$ for the chemical and radioactive waste) [26]. A study that was carried out in the Xanthi General Hospital in Greece, reported that the amount of total production of chemical waste is comprised of $1.8 \% \mathrm{w} / \mathrm{w}$ of the total hazardous medical waste produced by the hospital [30]. In another study conducted in hospitals of Southeast Nigeria, chemical waste generation level were $14.0 \%$ for government and $10.6 \%$ for private hospitals [5]. These differences in chemical waste generation in different studies can be explained by various implemented medical waste management and segregation system in 
hospitals. According to the legislation of medical waste management in Iran, chemical waste should be segregated from infectious waste and treated separately. But because of lack of proper treatment methods for this type of waste in hospitals and insufficient training for segregation, usually there is not a lot of attention present and proper segregation from other wastes is not implemented. Therefore, it is one of the weaknesses and problems of Iranian hospital waste management system. In addition, increased environmental risks, can trouble infectious waste treatment systems.

\subsection{Segregation and Storage}

According to the regulations, hospital managers have the duty of care to ensure that waste is kept under control at all times within a hospital and disposed safely either onsite or offsite. Proper segregation, and onsite storage are described in the instructions of hazardous medical wastes management. In hospitals of Iran, medical waste is being segregated in four groups including general waste with black bags, infectious waste with yellow bags, pharmaceutical and chemical waste with white or brown bags, and sharp waste with safety boxes. Results of current study indicate that in the private hospitals $2 \%$ did not have a storage room, $15 \%$ have improper storage rooms and $83 \%$ of private hospitals have appropriate storage rooms. In governmental hospitals $4 \%$ did not have storage rooms and $18 \%$ have improper and $78 \%$ have appropriate storage rooms.

\subsection{Infectious and Sharp Waste Treatment}

The safe treatment and disposal of hospital waste is a challenge in many developing countries. The choice of treatment system involves consideration of waste characteristics, technology capabilities and requirements, environmental and safety factors, and costs - many of which depend on local conditions [26]. An understanding of the waste category and its volume is vital before deciding the technology to be adopted. There are numerous medical waste disposal methods, such as incineration, Autoclave, hydroclave, steam sterilization, microwave sanitation, chemical disinfection, dry heat disinfection, disinfection with superheated steam and disposal on land [23]. In the recent years, use of the incinerators due to their toxic byproducts is no more favorable and their application is prohibited. Therefore, hospitals of Iran need to use non-incineration methods for infectious waste treatment. According to the waste management legislation, hospitals must treat the hazardous waste and then deliver it to the municipality. However, non- incineration technologies appear to emit fewer pollutants, are cost-effective, compact, and reliable and avoid secondary pollution [28]. Results of this study indicated that $85.2 \%$ and $75.71 \%$ of private and governmental hospitals, respectively, are equipped with a treatment systems. And $14.8 \%$ and $24.29 \%$ of private and governmental hospitals did not have treatment device and hazardous waste in these hospitals are disposed without treatment which this can result serious negative impacts on the public health and on the environment. The percentage and type of equipment that are used for the treatment of infectious and sharp waste in private hospitals, are shown in Figure 1.

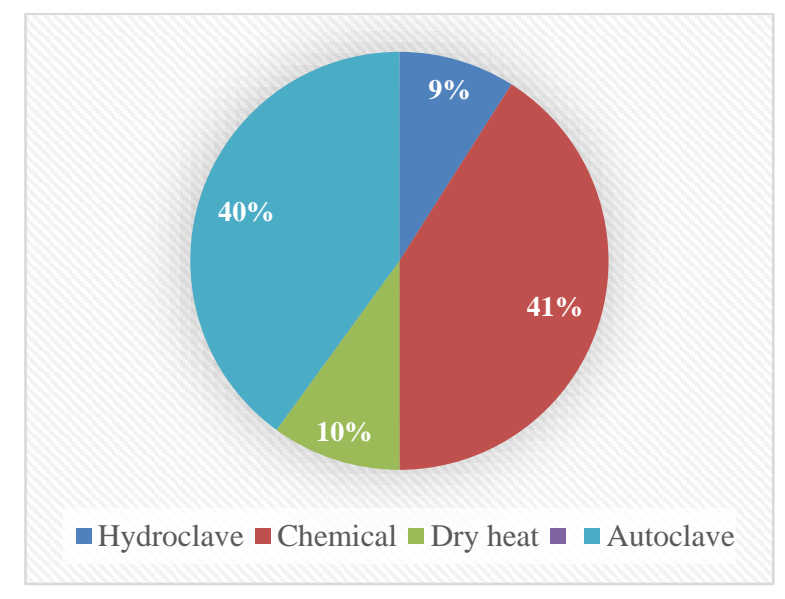

Figure 1. Private Hospitals' infectious and sharp waste treatment equipment

In the governmental hospitals, the use of autoclave is (40\%), hydroclave is (9\%), dry heat is (10\%) and chemical treatment methods is $(41 \%)$ that as shown in Figure 2. These methods are utilized for treatment of infectious and sharp wastes. Unlike of governmental hospitals most of private hospitals utilize autoclave (65\%) for infectious and sharp waste treatment. 


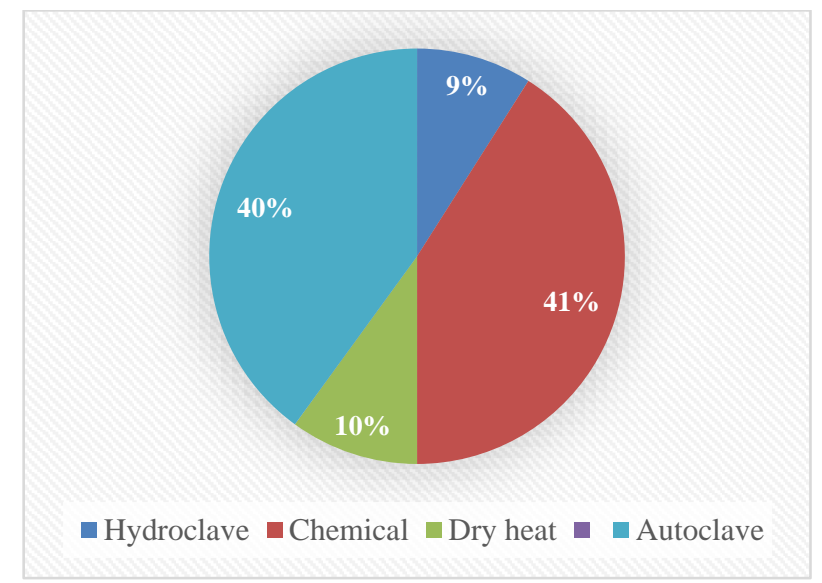

Figure 2. Governmental Hospitals' infectious and sharp waste treatment equipment

\subsection{Chemical-Hazardous Waste Treatment/Disposal}

Non-incinerated waste treatment devices such as autoclave is used for treating infectious-hazardous wastes in hospitals. Since these devices and methods are not used for chemical waste treatment in Iran, management of chemical waste is carried out by private companies. One of the main problems is the lack of reliable companies that treat and dispose chemical wastes.

\section{Conclusion}

Based on our analysis of hospital waste management, it became apparent that:

- The mean generation rates of total medical waste, hazardous-infectious and sharp waste, hazardous-chemical waste and general waste in private hospitals are 3.1, 0.99, 0.03 and, $2.07 \mathrm{~kg} / \mathrm{bed}$-day, respectively.

- The mean generation rates of total medical waste, hazardous-infectious and sharp waste, hazardous-chemical waste and general waste in governmental hospitals are 3.07, 1.13, 0.02 and, $1.89 \mathrm{~kg} / \mathrm{bed}$-day, respectively. Waste generation rate as well as differences in governmental and private hospitals is also related to many factors including the type of provided services for patient and their relatives.

- Percentage of hazardous-infectious and sharp waste $(36.9 \%)$ is higher than WHO and other countries estimated values that can be due to lack of waste minimization planning and improper segregation.

- Chemical waste management is a challenge of hospital waste managers.

- In private and governmental hospitals, $14.8 \%$ and $24.29 \%$ not have any treatment device and hazardous waste in these hospitals are disposed without treatment.

- Non-incineration methods are used in hospital waste treatment facilities in Iran and mostly autoclave, hydroclave and chemical methods are used.

\section{Acknowledgment}

The authors would like to thank the Student Research Committee of Shahid Beheshti University of Medical Sciences for funding support and the staff of the ministry of health and medical education and hospital environmental health experts for participating and contributing valuable comments during the development of the present study.

\section{References}

[1] Birpınar, Mehmet Emin, Mehmet Sinan Bilgili, and Tuğba Erdoğan. "Medical waste management in Turkey: A case study of Istanbul." Waste Management 29, no. 1 (2009): 445-448.

[2] Yong, Zhang, Xiao Gang, Wang Guanxing, Zhou Tao, and Jiang Dawei. "Medical waste management in China: a case study of Nanjing." Waste management 29, no. 4 (2009): 1376-1382.

[3] Geng, Yong, Wan-xia Ren, Bing Xue, Tsuyoshi Fujita, Feng-ming Xi, Ye Liu, and Mei-ling Wang. "Regional medical waste management in China: a case study of Shenyang." Journal of Material Cycles and Waste Management 15, no. 3 (2013): 310-320.

[4] Komilis, Dimitrios, Anastassia Fouki, and Dimitrios Papadopoulos. "Hazardous medical waste generation rates of different categories of health-care facilities." Waste Management 32, no. 7 (2012): 1434-1441.

[5] Oli, A.N, et al. "Healthcare waste management in selected government and private hospitals in Southeast Nigeria." Asian Pacific Journal of Tropical Biomedicine 6 (2016): 84-89. 
[6] Bdour, A, et al. "Assessment of medical wastes management practice: A case study of the northern part of Jordan." Waste Management 27 (2007): 746-759.

[7] Cheng, Y. W., F. C. Sung, Y. Yang, Y. H. Lo, Y. T. Chung, and K-C. Li. "Medical waste production at hospitals and associated factors." Waste Management 29, no. 1 (2009): 440-444.

[8] Manga, Veronica E., Osric Tening Forton, Linus A. Mofor, and Ryan Woodard. "Health care waste management in Cameroon: A case study from the Southwestern Region." Resources, Conservation and Recycling 57 (2011): 108-116.

[9] Qdais, H.A, Rabi A, and Abdulla F. "Characteristics of the medical waste generated at the Jordanian hospitals." Clean Technologies and Environmental Policy 9 (2007): 147-152.

[10] Maamari, Olivia, Cedric Brandam, Roger Lteif, and Dominique Salameh. "Health Care Waste generation rates and patterns: The case of Lebanon." Waste management 43 (2015): 550-554.

[11] Xin, Y. "Comparison of hospital medical waste generation rate based on diagnosis-related groups." Journal of Cleaner Production 100 (2015): 202-207.

[12] Sartaj, M. and Arabgol R. "Assessment of healthcare waste management practices and associated problems in Isfahan Province (Iran)." Journal of Material Cycles and Waste Management 17 (2015): 99-106.

[13] Da Silva, C, et al. "Medical wastes management in the south of Brazil." Waste management 25 (2005): 600-605.

[14] Taghipour, H and Mosaferi M. "Characterization of medical waste from hospitals in Tabriz, Iran." Science of The Total Environment 40 (2009): 1527-1535.

[15] Windfeld, E.S. and Brooks M.S.-L. "Medical waste management - A review." Journal of Environmental Management 163 (2015): 98-108.

[16] Oroei, M, et al. "A qualitative study of the causes of improper segregation of infectious waste at Nemazee Hospital, Shiraz, Iran." Journal of Infection and Public Health 7 (2014): 192-198.

[17] Khazaee, Manoochehr, Amir Hossein Hamidian, Mohmmad Taheri, Touran Babakan, Ali Mashoof, and A. Khazaee. "Assessment of medical waste management in Karaj hospitals, Iran." Inter Res J App Basic Sci 9, no. 10 (2015): 1750-57.

[18] Ministry of Health. "Instructions of complete and declaration of medical waste treatment and self-reported of hospitals. 2014.

[19] Askarian, M, Vakili M., and Kabir G. "Results of a hospital waste survey in private hospitals in Fars province, Iran." Waste management 24 (2004): 347-352.

[20] Windfeld, Elliott Steen, and Marianne Su-Ling Brooks. "Medical waste management-A review." Journal of environmental management 163 (2015): 98-108.

[21] Hadipour, M., et al. "Measurement and management of hospital waste in southern Iran: a case study." Journal of Material Cycles and Waste Management 16 (2014): 747-752.

[22] Tsakona, M, Anagnostopoulou E, and Gidarakos E. "Hospital waste management and toxicity evaluation: a case study." Waste management 27 (2007): 912-920.

[23] Diaz, L. F., L. L. Eggerth, S. H. Enkhtsetseg, and G. M. Savage. "Characteristics of healthcare wastes." Waste management 28, no. 7 (2008): 1219-1226.

[24] Komilis, D, Katsafaros N, and Vassilopoulos P. "Hazardous medical waste generation in Greece: case studies from medical facilities in Attica and from a small insular hospital." Waste Management \& Research 29 (2011): 807-814.

[25] Sanida, G, et al. "Assessing generated quantities of infectious medical wastes: A case study for a health region administration in Central Macedonia, Greece." Waste Management 30 (2010): 532-538.

[26] Chartier, Y, et al. "Safe management of wastes from health-care activities." 2013.

[27] Bazrafshan, E, and Mostafapoor F.K. "Survey of medical waste characterization and management in Iran: a case study of Sistan and Baluchestan Province." Waste Management \& Research 29 (2010): 442-450

[28] Ananth, A. Prem, V. Prashanthini, and C. Visvanathan. "Healthcare waste management in Asia." Waste Management 30, no. 1 (2010): 154-161.

[29] Mmereki, D, et al. "Healthcare waste management in Botswana: storage, collection, treatment and disposal system." Journal of Material Cycles and Waste Management 19 (2015): 1-15.

[30] Voudrias, E, et al. "Composition and production rate of pharmaceutical and chemical waste from Xanthi General Hospital in Greece." Waste Management 32 (2012): 1442-1452. 